\title{
Mineral fillers modified by shoulders from deodoration columns of oil and fat products
}

Chobit M., Vasylyev V., Panchenko Yu., Shabikova V.

Institute of Chemistry and Chemical Technologies, Lviv Polytechnic National University, UKRAINE, Lviv, 3/4 pl. Sviatoho Yura, e-mail: maksym.r.chobit@lpnu.ua

\begin{abstract}
The aim of the work was to investigate for the first time the possibility of modification of disperse mineral fillers (chalk and magnesium hydroxide) deodorizing shoulder straps containing fatty acids obtained by refining sunflower oil for create filled polymer composites.

Keywords - polymer composite, chalk, magnesium hydroxide, polyethylene, polyester resin, polyvinyl chloride.
\end{abstract}

For many decades, mankind has been using synthetic materials to replace natural ones. They are widely used because they have a number of advantages, namely, a significant variety of properties, low cost and the possibility of multi-ton production. A significant advantage of synthetic materials is the wide possibility of obtaining new materials having a significant list of different types of raw materials; the possibility of improving existing species. This can also be achieved by combining components of different origins and changing the technological parameters to obtain them. This path will improve the performance of synthetic materials under predetermined conditions and increase the list of opportunities for their technical application.

The oil and fat industry in Ukraine provides a wide range of oils and edible fats for various purposes. In the process of their processing, there is a significant amount of noncondensable fat-containing waste, which not be used for food purposes. That is why it is interesting to try to modification mineral fillers with fatty acids from deodorizing columns of oil and fat productions and to obtain polymeric composite filled with them.

The purpose of this work was to test the possibility of deodorizing shoulder straps containing fatty acids obtained by refining sunflower oil to modify mineral fillers: chalk and magnesium hydroxide.

Table. 1. Tensile strength of filled composites by polyvinyl chloride

\begin{tabular}{|c|c|c|c|c|}
\hline Filler & $\begin{array}{c}\text { Tensile } \\
\text { strength, MPa }\end{array}$ & $\begin{array}{c}\text { Increases of } \\
\text { tensile strength, } \\
\%\end{array}$ & $\begin{array}{c}\text { Relative } \\
\text { elongation, \% }\end{array}$ & $\begin{array}{c}\text { Increases of } \\
\text { relative } \\
\text { elongation, \% }\end{array}$ \\
\hline \multicolumn{5}{|c|}{ Chalk } \\
\hline Not modified & 1,92 & & 61,2 & - \\
\hline $\begin{array}{l}\text { Modified (degree of } \\
\text { modification } 2 \% \text { ) }\end{array}$ & 2,09 & 8,85 & 80,3 & 31,21 \\
\hline $\begin{array}{l}\text { Modified (degree of } \\
\text { modification } 5 \% \text { ) }\end{array}$ & 2,44 & 27,1 & 101,4 & 65,69 \\
\hline \multicolumn{5}{|c|}{ Magnesium hydroxide } \\
\hline Not modified & 1,83 & - & 70,8 & - \\
\hline $\begin{array}{c}\text { Modified (degree of } \\
\text { modification } 2 \% \text { ) }\end{array}$ & 2,15 & 17,5 & 89,5 & 30,56 \\
\hline $\begin{array}{c}\text { Modified (degree of } \\
\text { modification } 5 \% \text { ) }\end{array}$ & 2,65 & 44,8 & 125,4 & 89,22 \\
\hline
\end{tabular}


Study of the influence of the degree of modification of fillers on the physic-mechanical properties of polymer based on polyvinyl chloride (PVC), low density polyethylene (PENT) and polyester resin.

The tensile strength of polymeric composite materials based on PVC increases with increasing degree of modification, show in table 1. Accordingly, the relative elongation of the composites increases, i.e. the modification of the filler leads to an improvement in the mechanical properties of the composites, the higher content of the modifying agent increases this effect.

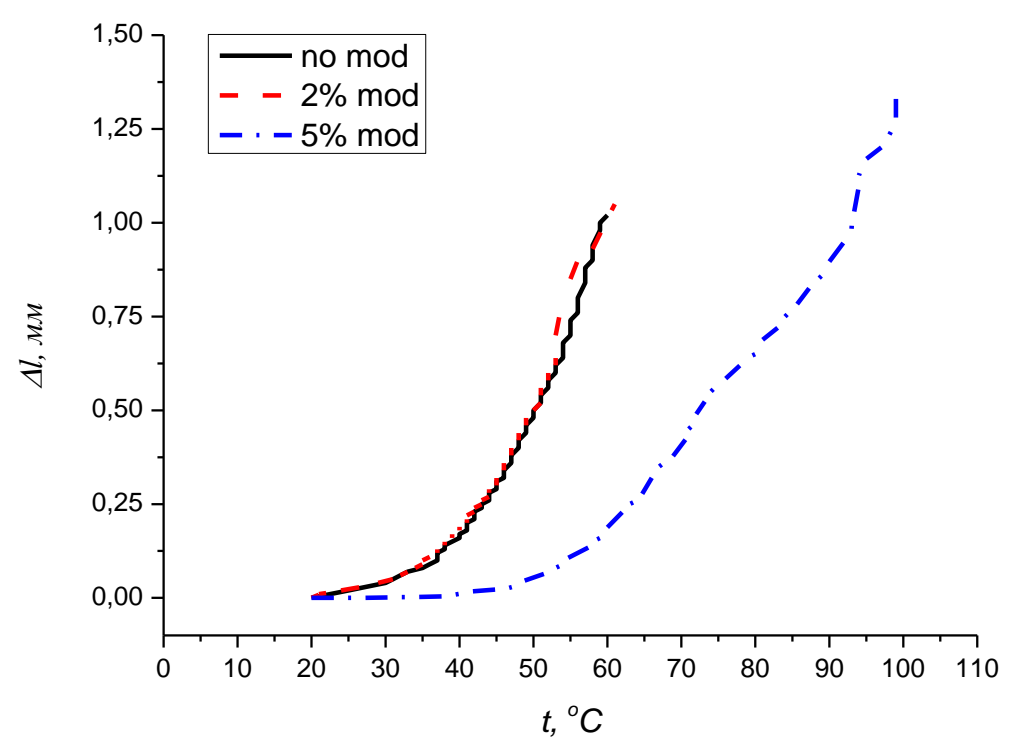

Fig.1. Thermomechanical properties of polymer composite materials polyester resin, filled by chalk: no modified, modified (degree of modification $2 \%$ and $5 \%$ ).

Polymer composite materials polyester resin filled by not modified chalk and chalk with degree of modification $2 \%$ the values of heat resistance are almost the same, show in Fig. 1. Sample of chalk with degree of modification 5\%, is an increase in heat resistance relative.

\section{Conclusion}

As a result of the conducted researches, for the first time the possibility of modification of dispersed mineral fillers (chalk and magnesium hydroxide) deodorizing shoulder straps of oil and fat productions was investigated. The aim of this process is further creation of filled polymer composites. Polymer composites based on PVC, PENT and polyester resin filled with modified fillers with different degrees of modification of $2 \%, 5 \%$ and $8 \%$ were obtained. The tensile strength of polymer composites, relative elongation, toughness and thermomechanical properties were studied. In the study of composites based on PVC, it is shown that with increasing degree of modification of the filler, their tensile strength increases, and the increase in strength reaches almost $50 \%$. It is established that the proposed method is not suitable for the creation of composites based on low density polyethylene, as there is a decrease in mechanical properties, at increasing the degree of modification impairs the strength of the composite. This effect is most likely due to the poor compatibility of the modified filler with the polymer matrix. Thermomechanical studies have shown that the heat resistance of composites with modified fillers generally increases. 